\title{
TUMOUR OF PITUITARY BODY WITHOUT ACROMEGALE.
}

BY EBNRST WILLB, M.D.LOND.

Assistant Madical Officer, County Arylum, Rainhill.

J. G., st. 26, cotton operative, was admitted into Rainhill Asylum, April 20th, 1891, suffering from dementia; he was very confused, his memory was defective, rendering him incepsble of giving any good account of himself, but he complained much of pains in his head. His facial expression was dull, somewhat anxious, and his general appearance cachectic. He looked younger than his age, was 4ft. 10in. in height and weighed 100lbs. His brother, who accompanied him to the asylum, also a short man, but taller than patient, healthy and fairly intelligent, gave the following information:

Family History.-They were both illegitimate children, mother dead, cause unknown, father living, healthy, now married. No insanity, consumption or cancer in family. on either side as far as informant knew.

Previous History. - Patient had never had any severe illnesses, or chest trouble. He had complained of pains in his head since he first began work at the mills fifteen years before. During the last six months they had become much worse, causing him to cry out at times "Oh, my head," and he had become very stupid. There had been no previous attack of insanity and no fits.

Condition on Admission. - Temperature normal. Well nourished generally. Skin elagtic, subcutaneous fat abundant. Circulatory system, heart sounds normal, pulse regular, moderate tension 68. Respiratory system normsl. Abdomen normal. No signs of syphilis. No albumen or sugar in the urine. Nervous system. External muscles of right eye normal, some paresis of left internal rectus with external strabismus. Irides hazel, margins circular and regular. Right pupil reacts to light and accommodation, 
left scarcely to either. Very little if any vision with the left eye. No paralysis of facial muscles, tongue protruded in middle line. No marked paralysis of limbs, but the grasp is distinctly feeble on both sides and a little weaker on the left than right. $\mathrm{He}$ is feeble on his legs, walking with a staggering gait and slight tendency to fall backward. Reflexes : the knee-jerks are present on both sides, the left being somewhat excessive. No ankle olonus. Superficial reflexes present, average, no marked difference between the two sides. Bensation to touch pain, and temperature is good all over. No hyperasthesia. There is consecutive optic atrophy of considerable duration in both discs, but especially well marked in the left.

April 30th.- Very dull and hesvy, lies in bed taking no notice of surroundings, crying out with pain accasionally. Has vomited two or three times. Has had no fits.

May 5th.-Brighter and more lively; although still confused and complaining of hesdaches, seys the pains are less severe.

May 12th.-Complains of recurrence of severe pains in the head and also in region of the left elbow; there is no neuritis. Vomited once to-day. No fits.

May 16th.-He wos very dull and lethargic, and had retraction of the head. After some hours he became comatose and died at night somewhat suddenly.

The following account of the tumour is from the report of the autopsy Dr. Gordon Sanders' (late pathologist to the asylum).

Post-mortem Examination;-Body squarely built, the hands short, broad and somewhat spade like, but all limbs fairly proportioned. There was a very large subcutaneous deposit of fat. There was nothing of any importance in any of the organs except the brain. The scalp was thick and hairy, the skull low, broad, rounded, of good symmetry, and natural thickness. On opening the skull and durs mater the cerebral hemispheres were seen to be flatter than natural ; on attempting to remove the brain a tumour was found at its base, in the region of the infundibulum, consisting of a dark soft greenish-yellow mass. The tumour could not be removed entire as a large part of it was wedged in the sella turcica, it was therefore cut across and this part dissected out afterwards. The brain itself seemed fairly normal, and presented no irregularity of convolutions, although on the vertex they seemed somewhat swollen and flat with considerable distension of veins; there was distinct diffused opacity of membranes, however, with much edhesion, in many parts reaching actual decortication, especially at the vertex. At the base of the brain within the 
interpeduncular space lay the tumour, extending anteriorly as far as the posterior termination of the orbital surface of the frontal lobes. Laterally it was overhung by the temporo-sphenoidal lobes. Posteriorly it extended to and separated widely the crurs cerebri. The greater mass of its substance lay eccentrically to the left and on separating the (apparent under but real) upper surface was found to lie in a hollow between the left frontal lobe and the left crus cerebri.

Position of Structures Rotnd,-Anteriorly the two olfactory nerves were thin and flattened, the left much the more so, of which the external root was alone visible as a thin whitish bend. The right optic tract skirted the right side of the tumour and was involved in the thickening of the capsule, the half of the optic chiasme on that side was seen lying just anterior to the projecting part of the tumour; it was white, tough and atrophied. The loft optic tract was very remarkably altered. It passed over the crus as a pale yellowish thin band and at once became involved in the tumour mass, being distinguished as \& soft yellowish ill-defined band passing forward obliquely to join the right tract in the chiasma, the left half of the chissma being soft, yellowish-grey, and translucent in marked contrast to the right. The crura cerebri were widely separated, the right was flattened and wasted, the left more displaced outwardly, more rounded and prominent. The corpora albicantia were pushed to the right side and much flattened, the right being nearly half the size of the left. The floor of the third ventricle and interpeduncular space semed softened by pressure, but were not implicated in the tumour. The pons seemed wasted and narrowed, the ventral pyramids were prominent, but the mesial sulcus was deep and the sides flattened. The medulla was possibly somewhat atrophied.

Description of Tumour. - It consisted of two parts connected by a pedicle, the upper part was removed with the brain, the remainder lay in the sella turcica and was dissected out after, and the sphenoid bone removed. The portion of tumour removed with the brain consisted of a soft glistening body the size of a Tangerene orange irregularly rounded or ovoid, about $3.5 \mathrm{~cm}$. in diameter and was divided into two unequal parts; a soft flatter darker basal portion of diameter referred to, and a more prominent hard yellowish spongiform body the size of a marble, somewhat gritty, seated in the right anterior segment (apparent left, as the brain lay with tumour uppermost), separated by narrow neck from the bassl portion. This second projecting portion was that which was continuous with the pituitary body and infundibulum. The 
whole tumour had a thin diatinct capsule unequal in thickness, more ill-defined and grayish over the basal part, but tough, thicker and whitish over the dependent portion, from which it was casily separable. The flatter basal portion was of varied colour; the left half being of greenish yellow hue, somewhat like a greengage in colour, across it posteriorly lay a large whitish yellow band, which proved to be the left optic tract; the right half was more distinct, yellower and firmer.

The bony floor of the sella turcica presented sharp elevations and ridges, and when the dora mater was stripped from them their summits were found rough and granular. The sella turcica was much broadened and its constituent bones remarkably thin, the basilar portion being a mere lamina and very brittle. The tumour here was very soft in its anterior half and lay entirely enclosed in a thick capsale, the posterior half was of deep canary yellow, rough, spongioid and the seat of a fairly recent hemorrhage. The anterior half or section was found to be a cyst containing a greenish yellow glistening fluid somewhet viscons. Although the floor of the sells turcica was pitted in several places into cavities the size of a split pea, at no point was there any communication with the buocal cavity from which the tumour was shut off by a mere shell of bone.

Microscopic examination of various parts of the tumour showed that it was composed of two parts, a minor solid and a much larger part, in fact the majority of the tumour, which wes cystic. A section of the solid or semi-solid portion of the tamour exhibited a structure resembling that of the thyroid body, viz., a cepsule of fibrons tissue with cleft like speces in it lined with flattened epithelium, an inner stroma of fibrous tissue containing small cysts of various sizes lined with columnar epithelium and the lumen of the cyst containing a viscid substance or filled with cells columnar, ovoid, or round. Nowhere in the specimens were any columns of cells spresding in a malignant manner, although there were here and there to be groups of cells somewhat resembling the nests in a carcinoma, these were probably only the walls of smaller oysts in the plane of the section.

Sections of the walls of the larger cysts only showed a fibrous stracture, with the cleft like spaces as mentioned above, and with patches of pigment here and there, the remains probably of old homorrhages as the fibrous tiasue was very vascular. 
Commentary.-This case has sereral points of great interest which make it worthy of record. 1. Clinically from the large size it attained, and the amonnc of displacement of sarrounding parts it caused without giving rise to any serious symptoms until quite late in the case. 2. The nature of the tumour itself. 3. The absence of any acromegale in association with the tamour of pitaitary body.

Clinically the principal symptoms were those usually found with cerebral tumour, headache, vomiting and optic neuritis with cunsecutive atrophy; but until his mental condition caused him to leave off work, he had managed very well as an operative in a mill and at no time had be any paralysis, nor did the almost total loss of sight with the left eye seem to have troubled him.

The organic dementia caused by the tamour is interesting, too, as most authorities agree that cerebral tumour as a cause of insanity is decidedly rare, although insenity as a sequence of tumour is fairly common. With respect to this point it may be mentioned that during the last twelve months there have been an exceptional number at Rainhill Asylum, viz., five cases in about 240 post-mortems-this of course is very much above the average.

With regard to the tumour itself, it seems to be what is called by some authors, gôitre of the pituitary body from its resemblance to the structure of the thyroid gland. Weigert calls it adenoma of the pituitary body and supposes it to be a cystic degeneration and hyperplastic overgrowth of the anterior lobe, which lobe in the adult normally contains a large number of convoluted tubules or alveoli lined with columnar epitheluim which in some cases fills up the tube; moreover portions of the tubules are frequently cut off by the connective tissue so as to form vesicles. The lymphatics of the organ originate in cleft like spaces between the tubules and pass to a network in the capsule (Quain's Anatomy, vol. 2). All these characters are represented in the present tamonr. With regard to acromegale, in many cases of that disease which have been published, hypertrophy of the pituitary body has been observed, and Dr. Pierre. 
Marie, in his paper on the subject, Brand, July, 1889, says, "Finally amongst the lesions affecting other organs, and which, after what has been observed in other autopsies, seem to me to be constant in acromegale, must be mentioned hypertrophy of the pituitary body with enormous dilatation of the sella turcica, persistence of the thymus and finally hypertrophy of the cord and ganglia of the sympathetic system." The two latter points were not specislly observed, but there were certainly no signs of acromegale about the patient. therefore as a negative case it seemed worth recording. 